\title{
Statistical Study Regarding Differences Between the Wax-Up, Mock-Up, and Final Restoration
}

\author{
Kinga Jánosi', Andrea Szász², Diana Cerghizan \\ 1 Department of Fixed Prosthodontics, Faculty of Dental Medicine, University of Medicine and Pharmacy, Tîrgu Mureș, Romania \\ 2 Dental student, Faculty of Dental Medicine, University of Medicine and Pharmacy, Tîrgu Mureș, Romania
}

\section{CORRESPONDENCE}

\section{Andrea Szász}

Str. Banat nr. 33/6

540486 Tîrgu Mureș, Romania

Tel: +40 740524383

E-mail: andiiszasz@gmail.com

\section{ARTICLE HISTORY}

Received: 3 March, 2017

Accepted: 7 March, 2017
Kinga Jánosi • Str. Gheorghe Marinescu nr. 38, 540139 Tîrgu Mureș, Romania, Tel: +40 265215551 Diana Cerghizan - Str. Gheorghe Marinescu nr. 38 , 540139 Tîrgu Mures, Romania, Tel: +40 265215551

\begin{abstract}
The aesthetic rehabilitation of patients remains a challenge for practicians. To facilitate the clinicians' and technicians' task, several innovative methods were developed, like the diagnostic wax-up and mock-up. The width-to-length ratio of the maxillary frontal teeth can be used to evaluate dentofacial aesthetics. Our study presents the variations between the teeth size measured on casts obtained during the prosthodontic treatment.
\end{abstract}

Keywords: wax-up, mock-up, final restoration

\section{INTRODUCTION}

The growing demand for dentofacial aesthetics is a trend; the patients' expectations on aesthetics increased and led to the appearance of different minimally invasive techniques in oral rehabilitation, focused on a natural look. One of the prosthodontic outcomes is the communication with the patient and the predictability of the dental treatments. A diagnostic wax-up represents a dental diagnostic procedure that ensures the direct communication between the patient, clinician and the dental laboratory in order to achieve the desired aesthetic. ${ }^{1}$

Mathematical formulas, conceptions and theories have been established regarding the selection of artificial teeth in the aesthetic rehabilitation of the frontal area, but without real success. Several studies describe the correct proportionality between frontal teeth dimensions as a major component in the appreciation of facial aesthetic. ${ }^{2} \mathrm{~A}$ harmonious aspect of the frontal view is determined by the size, shape and alignment of the maxillary frontal teeth. ${ }^{3}$

The "Golden Proportion", described and published by Levin and Lombardi in 1970 , is based on a correlation between natural beauty and mathematics, ${ }^{4-6}$ but it is a very controversial topic in dental medicine, as several authors have argued that the "Golden Proportion" does not exist. ${ }^{7-10}$ 
The patients should be examined from the frontal view, in dynamic mandibular movements, such as conversation, facial expression and smile, to assess facial aesthetics. ${ }^{11}$ For this reason, most clinicians prefer to take videos instead of photos. ${ }^{12}$

\section{MATERIAL AND METHOD}

Two patients of similar ages (a female and a male) with similar intraoral status were included in the study. The patients needed an oral rehabilitation to solve an advanced tooth wear on their maxillary frontal teeth. Informed consent was obtained prior to their participation in this study, which has been approved by the institutional Ethics Committee.

Repeated maxillary arch impressions were made for both patients by the same person using metal stock trays with irreversible hydrocolloid impression material (Tropicalgin, Zhermack, Badia Polesine, Italy), based on the following protocol: application of the tray adhesive - Universal Tray Adhesive (Zhermack) for 5 minutes, the same chamber temperature, same mixing time of the impression material, way of application in the mouth and similar maintenance time according the set of the material). After the removal of the trays the impressions were washed and disinfected (Zeta 7 Spray, Zhermack), and they were taken to the laboratory where the casts were made with type IV dental stone (Pro Stone 21, Saint-Gobain Formula, Balderton, UK), using a mechanical vibrator to eliminate the air bubbles.

After the casts had been obtained, three different technicians made wax-up according to the restoration of the maxillary frontal teeth, without having any information about the patients. This way we obtained wax-up models, which were transformed into mock-ups based on a preliminary impression with a condensation silicone material (Zetaplus, Oranwash, Zhermack). The mock-ups were manufactured from a self-cure composite material (Structur 3, color A2, Voco, Cuxhaven, Germany). The mock-ups were examined by the clinician and the patients, the ones that were the closest to the dentofacial aesthetic were chosen and modified in the mouth. Then, impressions were taken with an irreversible hydrocolloid material in order to obtain a stone cast of the final mock-up that served for the treatment plan of the final restorations. After the crowns' cementation, other impressions were taken, and the final casts were also examined.

\section{Tooth dimension measurements}

The length and width of the six maxillary frontal teeth were measured on the dental casts with a digital caliper
(Fixpoint, $150 \mathrm{~mm}$, with an accuracy of $0.01 \mathrm{~mm}$, Fixpoint, Wentronic, Germany), with and without magnification (Perioptix, 2.7x). The measurements were carried out three times by two different persons, and an average was taken. All measurements were done on the facial surface using the millimetric scale.

After scanning the casts digitally in 3D, the length and width of the maxillary frontal teeth were measured with the 3D Builder software (Microsoft Corporation, Redmond, Washington, USA).

To measure the crown length, a reference line was drawn on the cast, parallel with the occlusal plane. The measurements were made starting from the point where this line intersects the gingival zenith, on the long axis of the tooth, towards the incisal edge.

The width of the teeth was measured on the longest diameter of the clinical crown between the mesial and distal contact points, on a line perpendicular to the long axis of the tooth.

\section{Proportionality measurements}

Proportionality measurements were made in the Digimizer software on standardized photographs obtained using a Nikon D600 camera (Macro Nikkor lens, f18, ISO 200, shutter speed 1/125) with a tripod stand, as well as photographs from the $3 \mathrm{D}$ scans. The casts were set parallel to the occlusal plane.

The data were introduced in Microsoft Excel 2013. The mean and standard deviation of the length and width were calculated. The Kruskal-Wallis test and one-way ANOVA were used, and the statistical significance was set at $\mathrm{p}$ $<0.05$. Dunn's multiple comparisons test and the TukeyKramer multiple comparisons test were used as a post-hoc analysis when a significant difference was identified.

\section{RESULTS}

In the first patient there were no statistically significant differences between the first wax-up model and the initial stage when we compared the mean values of the length of the maxillary frontal teeth. Aside from the mean value of the length of the left canine, none of the values showed statistically significant differences on the second wax-up and mock up model (Tables 1 and 2).

Regarding the mean values of the width measured on the first wax-up $(8.4911 \pm 0.2559)$, there were no statistically significant differences compared with those obtained on the second wax-up $(8.2722 \pm 0.1084)$ and mock-up $(8.4156 \pm 0.1245)$ for the right central incisor. 
TABLE 1. Length of teeth in the anterior segment of the maxilla (mean $\pm \mathrm{SD} m \mathrm{~m}$ ) - first case

\begin{tabular}{lcccccc}
\hline & First wax-up & Second wax-up & Third wax-up & Mock-up & Initial & Final \\
\hline Right canine & $7.2800 \pm 0.4175$ & $7.9750 \pm 0.1252$ & $8.0583 \pm 0.2731$ & $7.9025 \pm 0.1239$ & $6.0100 \pm 0.1377$ & $7.9925 \pm 0.1660$ \\
Right central incisor & $6.4543 \pm 0.2543$ & $7.4108 \pm 0.3034$ & $6.9742 \pm 0.1406$ & $7.3608 \pm 0.1517$ & $5.1208 \pm 0.1617$ & $6.8358 \pm 0.2145$ \\
Right lateral incisor & $6.7383 \pm 0.3394$ & $7.7408 \pm 0.1989$ & $7.1208 \pm 0.3424$ & $7.9592 \pm 0.1661$ & $5.6700 \pm 0.2907$ & $7.6142 \pm 0.1396$ \\
Left central incisor & $6.8842 \pm 0.3332$ & $7.8050 \pm 0.2107$ & $7.4658 \pm 0.2347$ & $8.4442 \pm 0.1272$ & $5.7817 \pm 0.2370$ & $7.6150 \pm 0.2533$ \\
Left lateral incisor & $6.3767 \pm 0.2806$ & $7.2300 \pm 0.3397$ & $7.5558 \pm 0.2333$ & $7.7833 \pm 0.2201$ & $5.6392 \pm 0.1407$ & $7.1417 \pm 0.1122$ \\
Left canine & $7.2225 \pm 0.3846$ & $8.0458 \pm 0.3999$ & $8.4608 \pm 0.2007$ & $8.9242 \pm 0.3628$ & $6.8575 \pm 0.2533$ & $8.9308 \pm 0.1102$ \\
\hline
\end{tabular}

TABLE 2. Post-hoc analysis results for the first case

\begin{tabular}{|c|c|c|c|c|c|c|}
\hline & First wax-up & Second wax-up & Third wax-up & Mock-up & Initial & Final \\
\hline & \multicolumn{6}{|c|}{ Mean rank difference } \\
\hline Wax-up 1 vs. Wax-up 2 & $-28.125^{*}$ & $-41.833^{* * *}$ & $-31.176^{* *}$ & $-30.125^{* *}$ & $-22.333 \mathrm{~ns}$ & -15.333 ns \\
\hline Wax-up 1 vs. Wax-up 3 & $-33.083^{* *}$ & $-21.167 \mathrm{~ns}$ & $-7.583 \mathrm{~ns}$ & -15.833 ns & $-34.417^{* * *}$ & $-24.167 \mathrm{~ns}$ \\
\hline Wax-up1 vs. Mock-up & $-21.992 \mathrm{~ns}$ & $-39.917^{* * *}$ & $-42.750^{* * *}$ & $-46.875^{* * *}$ & $-44.917^{* * *}$ & $-42.042^{* * *}$ \\
\hline Wax-up1 vs. Initial & 13.459 ns & $12.208 \mathrm{~ns}$ & $14.625 \mathrm{~ns}$ & 13.125 ns & $12.000 \mathrm{~ns}$ & 7.083 ns \\
\hline Wax-up 1 vs. Final & $-29.708^{* *}$ & $-16.042 \mathrm{~ns}$ & $-25.375^{*}$ & $-21.542 \mathrm{~ns}$ & $-18.888 \mathrm{~ns}$ & $-45.292^{* * *}$ \\
\hline Wax-up 2 vs. Wax-up 3 & $-4.958 \mathrm{~ns}$ & $20.667 \mathrm{~ns}$ & $23.583 \mathrm{~ns}$ & $14.292 \mathrm{~ns}$ & $-12.083 \mathrm{~ns}$ & $-8.833 \mathrm{~ns}$ \\
\hline Wax-up 2 vs. Mock-up & $6.333 \mathrm{~ns}$ & $1.917 \mathrm{~ns}$ & $-11.583 \mathrm{~ns}$ & $-16.750 \mathrm{~ns}$ & $-22.583 \mathrm{~ns}$ & $-26.708^{*}$ \\
\hline Wax-up 2 vs. Initial & $41.583^{* * *}$ & $54.042^{* * *}$ & $45.792^{* * *}$ & $43.250^{* * *}$ & $34.333^{* * *}$ & $22.417 \mathrm{~ns}$ \\
\hline Wax-up 2 vs. Final & $-1.583 \mathrm{~ns}$ & $25.792^{*}$ & 5.792 ns & $8.583 \mathrm{~ns}$ & $4.000 \mathrm{~ns}$ & $-29.968^{* *}$ \\
\hline Wax-up 3 vs. Mock-up & $11.292 \mathrm{~ns}$ & $-18.750 \mathrm{~ns}$ & $-35.167^{* * *}$ & $-31.042^{* *}$ & $-10.500 \mathrm{~ns}$ & $-17.875 \mathrm{~ns}$ \\
\hline Wax-up 3 vs. Initial & $46.542^{* * *}$ & $33.375^{* *}$ & $22.208 \mathrm{~ns}$ & $28.958^{*}$ & $46.417^{* * *}$ & $31.250^{* *}$ \\
\hline Wax-up 3 vs. Final & 3.375 ns & $5.125 \mathrm{~ns}$ & -17.792 ns & $-5.708 \mathrm{~ns}$ & 16.083 ns & $-21.125 \mathrm{~ns}$ \\
\hline Mock-up vs. Initial & $35.250^{* * *}$ & $52.125^{* * *}$ & $57.375^{* * *}$ & $60.000^{* * *}$ & $56.917^{* * *}$ & $49.125^{* * *}$ \\
\hline Mock-up vs. Final & $-7.917 \mathrm{~ns}$ & $23.875 \mathrm{~ns}$ & $17.375 \mathrm{~ns}$ & $25.999^{*}$ & $26.583^{*}$ & $-3.250 \mathrm{~ns}$ \\
\hline Initial vs. Final & $-43.167^{* * *}$ & $-28.250^{*}$ & $-40.000^{* * *}$ & $-34.667^{* * *}$ & $-30.333^{* *}$ & $-52.375^{* * *}$ \\
\hline
\end{tabular}

${ }^{* * *}$ extremely statistically significant, ${ }^{* *}$ highly statistically significant, ${ }^{*}$ statistically significant, ns - not statistically significant

Regarding the mean values of the width of the right lateral incisor, we found a statistically significant difference between the measurements recorded on the first wax-up (6.7589 \pm 0.1621$)$, the third wax-up $(7.54 \pm 0.1626)$ and the final stage (7.37 \pm 0.0803$)$. Similar results were obtained between the values recorded on the third wax-up, mock-up $(7.1122 \pm 0.1464)$, initial $(6.7867 \pm 0.0487)$ and final stage.

Most of the mean values of the width of the right canine measured on the six models showed no statistically significant difference, except those recorded in the second waxup (7.7478 \pm 0.0755$)$ compared with the third wax-up (7.90 $\pm 0.1082)$ and the final stage $(8.1822 \pm 0.1489)$.

On the left part of the anterior maxillary arch, were found no statistically significant differences comparing the mean value of the width of the central incisor measured on the first $(8.5522 \pm 0.1462)$ and the third wax-up (8.6211 \pm $0.0998)$. Similar results were obtained comparing the measurements of the second wax-up $(8.37 \pm 0.0811)$ with those of the mock-up (8.3611 \pm 0.1117$)$ and initial stage (8.3467 $\pm 0.0907)$. There was no statistically significant difference between the third wax-up and the final stage $(8.7278 \pm$ 0.1279), as well as the mock-up and initial stages. On the first wax-up the mean values of the width of the lateral incisor $(6.6333 \pm 0.1332)$ showed a statistically significant difference compared with those recorded on the second wax-up (7.2211 \pm 0.1029$)$, third wax-up $(7.4589 \pm 0.0401)$ and mock-up (7.14 \pm 0.0995$)$. The mean values of the same tooth measured on the second wax-up showed a statistically significant difference compared with those recorded on the first cast $(6.9733 \pm 0.1181)$. The mean values of the width of the canine measured on the first wax-up $(8.1156 \pm 0.1395)$ and mock-up $(7.7233 \pm 0.1230)$ showed a statistically significant difference compared with those recorded on the initial $(7.4733 \pm 0.9461)$ and final stages $(7.3022 \pm 0.0726)$.

In the second patient, the mean values of the length measured on the first wax-up showed no statistically significant differences compared with those registered in the initial stage for the right canine, the right lateral, the cen- 
TABLE 3. Length of teeth in the anterior segment of the maxilla (mean $\pm \mathrm{SD} m \mathrm{~m}$ ) - second case

\begin{tabular}{lcccccc}
\hline & First wax-up & Second wax-up & Third wax-up & Mock-up & Initial & Final \\
\hline Right canine & $9.6600 \pm 0.1320$ & $9.2075 \pm 0.3629$ & $10.3050 \pm 0.2851$ & $10.2883 \pm 0.2779$ & $9.5558 \pm 0.1192$ & $10.3208 \pm 0.2779$ \\
Right central incisor & $7.1858 \pm 0.2365$ & $7.5658 \pm 0.1882$ & $7.8233 \pm 0.1802$ & $8.3692 \pm 0.3654$ & $7.0167 \pm 0.1131$ & $8.3692 \pm 0.3654$ \\
Right lateral incisor & $8.0942 \pm 0.1635$ & $8.1792 \pm 0.2201$ & $8.7200 \pm 0.1415$ & $8.9533 \pm 0.1685$ & $7.7392 \pm 0.2820$ & $8.9533 \pm 0.1685$ \\
Left central incisor & $8.0700 \pm 0.1143$ & $8.1100 \pm 0.2046$ & $8.0467 \pm 0.1139$ & $8.6908 \pm 0.1497$ & $6.2925 \pm 0.1622$ & $8.6908 \pm 0.1497$ \\
Left lateral incisor & $7.1267 \pm 0.1114$ & $7.3808 \pm 0.2348$ & $7.7392 \pm 0.1645$ & $8.1417 \pm 0.1384$ & $6.1892 \pm 0.2507$ & $8.1417 \pm 0.1384$ \\
Left canine & $8.3983 \pm 0.2120$ & $9.0350 \pm 0.1808$ & $9.4025 \pm 0.1615$ & $9.2858 \pm 0.1554$ & $8.6417 \pm 0.1615$ & $9.2858 \pm 0.1554$ \\
\hline
\end{tabular}

TABLE 4. Post-hoc analysis results for the second case

\begin{tabular}{|c|c|c|c|c|c|c|}
\hline & First wax-up & Second wax-up & Third wax-up & Mock-up & Initial & Final \\
\hline & \multicolumn{6}{|c|}{ Mean rank difference } \\
\hline Wax-up 1 vs. Wax-up 2 & $0.4525^{* * *}$ & $-16.167 \mathrm{~ns}$ & $-4.667 \mathrm{~ns}$ & $-3.833 \mathrm{~ns}$ & $-9.500 \mathrm{~ns}$ & $-0.6367^{* * *}$ \\
\hline Wax-up 1 vs. Wax-up 3 & $-0.6450^{* * *}$ & $-31.458^{* *}$ & $-32.917^{* *}$ & $3.167 \mathrm{~ns}$ & -22.083 & $-1.004^{* * *}$ \\
\hline Wax-up1 vs. Mock-up & $-0.6283^{* * *}$ & $-46.750^{* * *}$ & $-43.333^{* * *}$ & $-32.208^{* *}$ & $-42.333^{* * *}$ & $-0.8875^{* * *}$ \\
\hline Wax-up1 vs. Initial & $0.1042 \mathrm{~ns}$ & 7.083 ns & 10.917 ns & $27.792^{*}$ & 14.083 ns & $-0.2433^{* * *}$ \\
\hline Wax-up 1 vs. Final & $-0.6608^{* * *}$ & $-31.458^{* *}$ & $-22.500 \mathrm{~ns}$ & $-8.167 \mathrm{~ns}$ & $-35.667^{* * *}$ & $-1.629^{* * *}$ \\
\hline Wax-up 2 vs. Wax-up 3 & $-1.098^{* * *}$ & $-15.292 \mathrm{~ns}$ & $-28.250^{*}$ & $7.000 \mathrm{~ns}$ & $-12.583 \mathrm{~ns}$ & $-0.3675^{* * *}$ \\
\hline Wax-up 2 vs. Mock-up & $-1.081^{* * *}$ & $-30.583^{* *}$ & $-38.667^{* * *}$ & $-28.375^{*}$ & $-32.833^{* *}$ & $-0.2508^{*}$ \\
\hline Wax-up 2 vs. Initial & $0.3483^{*}$ & $23.250 \mathrm{~ns}$ & 15.583 ns & $31.625^{* *}$ & 23.583 ns & $0.3933^{* * *}$ \\
\hline Wax-up 2 vs. Final & $-1.113^{* * *}$ & $-15.292 \mathrm{~ns}$ & -17.833 ns & $-4.333 \mathrm{~ns}$ & $-26.167^{*}$ & $-0.9925^{* * *}$ \\
\hline Wax-up 3 vs. Mock-up & $0.01667 \mathrm{~ns}$ & $-15.292 \mathrm{~ns}$ & $-10.417 \mathrm{~ns}$ & $-35.375^{* * *}$ & $-20.250 \mathrm{~ns}$ & $0.1167 \mathrm{~ns}$ \\
\hline Wax-up 3 vs. Initial & $0.7492^{* * *}$ & $38.542^{* * *}$ & $48.833^{* * *}$ & $24.625 \mathrm{~ns}$ & $36.167^{* * *}$ & $0.7608^{* * *}$ \\
\hline Wax-up 3 vs. Final & $-0.0158 \mathrm{~ns}$ & $0.000 \mathrm{~ns}$ & 10.417 ns & -11.333 ns & -13.583 ns & $-0.6250^{* * *}$ \\
\hline Mock-up vs. Initial & $0.7325^{* * *}$ & $53.833^{* * *}$ & $54.250^{* * *}$ & $60.000^{* * *}$ & $56.417^{* * *}$ & $0.6442^{* * *}$ \\
\hline Mock-up vs. Final & $-0.0325 \mathrm{~ns}$ & $15.292 \mathrm{~ns}$ & 20.833 ns & 24.042 ns & $6.667 \mathrm{~ns}$ & $-0.7417^{* * *}$ \\
\hline Initial vs. Final & $-0.765^{* * *}$ & $-38.542^{* * *}$ & $-33.417^{* *}$ & $-35.958^{* * *}$ & $-49.750^{* * *}$ & $-1.386^{* * *}$ \\
\hline
\end{tabular}

${ }^{* * *}$ extremely statistically significant, ${ }^{* *}$ highly statistically significant, ${ }^{*}$ statistically significant, ns - not statistically significant

tral incisor and the left lateral incisor. Most of the mean values obtained by measuring on the third wax-up were not different from those recorded on the mock-up (Tables 3 and 4).

There were no statistically significant differences between the mean values of the width of the right central incisor. For the right lateral incisor, the mean values measured on the first wax-up $(6.8367 \pm 0.0999)$ showed a statistically significant difference when compared with those registered on the second wax-up $(7.3111 \pm 0.1379)$, the third wax-up $(7.1422 \pm 0.1328)$ and mock-up (7.2611 \pm 0.0777$)$. Similar results were obtained for the right canine. Measurements of the right lateral incisor made on the second wax-up and mock-up were different from those recorded on the initial stage (6.9009 \pm 0.0734$)$. In the case of the right canine we also found a statistically significant difference between the mean values measured on the third wax-up $(9.1633 \pm$ $0.1141)$, the initial $(8.22 \pm 0.0665)$ and the final stage $(8.1344$ $\pm 0.0686)$. For the left central incisor, the mean values ob- tained in the final stage $(8.9567 \pm 0.0626)$ were statistically different compared with the first $(8.7056 \pm 0.0711)$, the second $(8.6556 \pm 0.1057)$, the third wax-up $(8.6956 \pm 0.0321)$, mock-up (8.7278 \pm 0.1618$)$ and the initial stage $(8.7056 \pm$ $0.0274)$. Otherwise, there were no statistical differences. There were no statistically significant differences regarding the width of the left lateral incisor between the first (7.0944 $\pm 0.1571)$, the second (7.0944 \pm 0.0862$)$, the third wax-up $(7.1311 \pm 0.1623)$ and final restoration $(7.0333 \pm 0.1234)$. For the left canine, the mean values of the width measured on the first $(8.2089 \pm 0.1132)$ and second wax-up (8.2256 \pm $0.1203)$ were statistically different from those measured in the final stage $(8.722 \pm 8.1873)$. A statistical difference was also found analyzing the mean values recorded on the third wax-up (8.4956 \pm 0.2015$)$, mock-up $(8.3833 \pm 0.0850)$, and the initial stage $(8.0811 \pm 0.1200)$.

The width-to-length ratio calculated for the central incisors and all maxillary frontal teeth (mean values for all measurements) are presented in Tables 5 and 6. 
TABLE 5. Central incisor width-to-length ratio

\begin{tabular}{lcccccc}
\hline \multirow{2}{*}{ Central incisor } & \multicolumn{3}{c}{ First case } & \multicolumn{3}{c}{ Second case } \\
\cline { 2 - 7 } & Right & Left & Average & Right & Left & Average \\
\hline Wax-up 1 & $126 \%$ & $124 \%$ & $125 \%$ & $107 \%$ & $108 \%$ & $107.5 \%$ \\
Wax-up 2 & $106 \%$ & $107 \%$ & $106.5 \%$ & $107 \%$ & $105 \%$ & $106 \%$ \\
Wax-up 3 & $120 \%$ & $110 \%$ & $115 \%$ & $99 \%$ & $108 \%$ & $103.5 \%$ \\
Mock-up & $105 \%$ & $109 \%$ & $107 \%$ & $97 \%$ & $100 \%$ & $98.5 \%$ \\
Initial & $146 \%$ & $143 \%$ & $144.5 \%$ & $111 \%$ & $138 \%$ & $124.5 \%$ \\
Final & $112 \%$ & $113 \%$ & $112.5 \%$ & $103 \%$ & $109 \%$ & $106 \%$ \\
\hline
\end{tabular}

\section{DISCUSSION}

The essential component of natural appearance is individual beauty. The concept of beauty is considered one of the most controversial subjects in literature. Dentofacial aesthetics is a determinating factor of personality. The first study about dental aesthetics regarding teeth alignment was published in 1872 by J.W. White. ${ }^{13}$

Different tooth proportions were evaluated in several studies concerning harmonious dentofacial aesthetics. Maxillary frontal teeth width variations from frontal view are defined by the Golden Proportion theory, according to which the lateral incisor should represent $62 \%$ of the width of the maxillary central incisor, and the canine should represent $62 \%$ of the width of the resulting lateral incisor. ${ }^{7}$

In our study, the ratios of the average values obtained from 3D models and digital photograph measurements were not within the Golden Proportion, and this percentage is not characteristic for dental medicine, as Preston and Snow demonstrated in their study. ${ }^{10,14}$

In both cases, there was no concordance between the values obtained on different models regarding the right and the left side of the maxilla. The Golden Proportion could not be recognized in any of the teeth. Our ratios were closer to the Preston proportion, meaning that in frontal view the width of the lateral incisor and upper canine is $66 \%$ and $55 \%$ of the maxillary central incisor width, respectively. ${ }^{10}$ In the first case our values were: right lat-

TABLE 6. Average of the width-to-length ratio for all teeth

\begin{tabular}{lcc}
\hline & First case & Second case \\
\hline Wax-up 1 & $113 \%$ & $98 \%$ \\
Wax-up 2 & $100 \%$ & $98 \%$ \\
Wax-up 3 & $104 \%$ & $95 \%$ \\
Mock-up & $95 \%$ & $90 \%$ \\
Initial & $128 \%$ & $106 \%$ \\
Final & $100 \%$ & $92 \%$ \\
\hline
\end{tabular}

eral incisor $70.62 \%$, right canine $55.92 \%$, left lateral incisor $69.02 \%$, left canine $50.82 \%$, and in the second case: right lateral incisor $69.99 \%$, right canine $56.72 \%$, left lateral incisor $70.90 \%$, left canine $67.97 \%$.

The evaluation of tooth size proportionality could serve for the establishment of a predictable treatment plan and an accurate clinical diagnosis.

The width-to-length ratio of the maxillary central incisors is significant in dental appearance, because these teeth dominate the smile and contribute to the determination of personality. The central incisor is in the Golden Proportion if the coronal width-to-length ratio is $62 \% .{ }^{15}$

In several studies, the width-to-length ratio has been considered aesthetic if this value varied between $75-$ $80 \% .3,16$ Our results concerning the central incisors did not show these proportions. In the first case the closest values were obtained at the second wax-up (106.5\%), which was used for the treatment plan. We found differences between the first wax-up (125\%) and the mock-up (107\%) obtained by modifying the second wax-up intraorally, and also by comparing these proportions with the values of the final restorations (112.5\%). Between the initial (144.5\%) and final values, those of the final restorations are close to the aesthetic proportion, but with a considerable difference.

In the second case, we found that the obtained ratios differ at the third wax-up (103.5\%), which was used for the treatment plan, the mock-up (98.5\%) and the final restorations $(106 \%)$. The mock-up ratios were the most appropriate to the aesthetic proportion (75-80\%). The final restoration proportions were more aesthetic compared with the initial ratios (124.5\%), but still not comparable to the aesthetic percentage.

Comparing the averages of the width-to-length ratios calculated for each model, in both cases the mock-up ratios were closer to the aesthetic percentage. The ratios are mentioned in studies carried out by Vinicus et al. ${ }^{17}$ (75-80\%) and Magne et al. ${ }^{18}$ (80\%), but there is still a dis- 
crepancy between the values. Our values are closer to the values obtained by Sterrett et al. ${ }^{19}(85-86 \%)$ and Hasanreioglu et al. $(88-91 \%){ }^{20}$

Raj specified in his study that the canines frequently present size and shape asymmetry even in an aesthetic smile, fact proved in our research. ${ }^{21}$ In the first case, only the length of the left canine differed from the second waxup that was used for the treatment plan, and the mock-up compared with all other values. Our results demonstrate that there are no statistically significant differences between the wax-up used to manufacture the mock-up and the final fixed restorations.

Similar results were obtained in the second case, with concordance between the third wax-up (used for the treatment plan), the mock-up and restorations values. Among these results, there were a few that did not follow this tendency. The reason for this could be related to human factors - not being able to reproduce exactly the tooth morphology, as well as to the physical and chemical characteristics of the materials used for the impression, cast, wax-up, mock-up and final restoration, as demonstrated in a study by Abduo, who recommends digital modeling of the teeth. ${ }^{22}$

Most of the results obtained in this study showed that it was not necessary to reshape the width of the teeth, due to the lack of space.

Tarvade considered that the mathematical relationship of frontal teeth is an important determinating factor in obtaining an aesthetic restoration. ${ }^{23,24}$ Our results do not confirm this; the obtained percentages were not similar with the values obtained by a mathematical formula. However, the subjective evaluation of the patients, the team and the patients' relatives has shown a good aesthetical restoration.

\section{CONCLUSIONS}

The aesthetic standards are not applicable in all cases. The patients included in this study and their reveals were pleased with the final restorations, which are considered anesthetics according to the mathematical formulas. The dental technician may have the ability to achieve aesthetic restorations, but the clinician and the patient take the final decision regarding the dentofacial aesthetics in all cases. Is difficult to obtain a similar morphology on final fixed prosthodontics even if the dental technician with artistic abilities had a perfect mock-up as a guide.

\section{REFERENCES}

1. Shenoy A, Shenoy N. Dental ceramics: An update. J Conserv Dent. 2010;13:195-203.

2. Wolfart S, Thormann H, Freitag S, Kern M. Assessment of dental appearance following changes in incisor proportions. Eur $J$ Oral Sci. 2005;113:159-165.

3. Ward DH. Proportional smile design using the recurring esthetic dental (red) proportion. Dent Clin North Am. 2001:45:143-154.

4. Levin El. Dental Esthetics and Golden Proportion. J Prosthet Dent 1978;40:244-252

5. Fradeani M. Esthetic Analysis - A systematic approach to Prosthetic Treatment. Vol 1. Milano, Italy: Quintessence Pub Co; 2004.

6. Lombardi RE. The principles of visual perception and their clinical application to denture esthetics. J Prosthet Dent. 1973;29:358-382.

7. Mahshid M, Khoshvaghti A, Varshosaz M, Vallaei N. Evaluation of "golden proportion" in individuals with an esthetic smile. J Esthet Restor Dent 2004:16:185-192.

8. Ward DH. A study of dentists' preferred maxillary anterior tooth width proportions: comparing the recurring esthetic dental proportion to other mathematical and naturally occurring proportions. J Esthet Restor Dent 2007:19:324-337.

9. Isa ZM, Tawfiq OF, Noor NM, et al. Regression methods to investigate the relationship between facial measurements and widths of the maxillary anterior teeth. J Prosthet Dent. 2010;103:182-188.

10. Preston JD. The Golden Proportion revisited. Journal Esthet Den. 1993;5:247-251.

11. Ku JE, Yang HS, Yun KD. A morphometric analysis of maxillary central incisor on the basis of facial appearance in Korea. J Adv Prosthodont 2012:4:13-17.

12. Walder JF, Freeman K, Lipp MJ, Nicolay OF, Cisneros GJ. Photographic and videographic assessment of smile: objective and subjective evaluations of posed and spontaneous smiles. Am J Orthod Dentofacial Orthop. 2013;144:793-801.

13. White JW. Aesthetic dentistry. Dent Cosmos. 1872;14:144-145.

14. Snow SR. Esthetic smile analysis of anterior tooth width: the golden percentage. J Esthet Dent. 1999:11:177-184

15. Brisman AS. Esthetics: A comparison of dentists' and patients' concepts. $J$ Am Dent Assoc. 1980:100:345-352.

16. Davis NC. Smile design. Dent Clin North Am. 2007;51:299-318

17. Vinicus M, De Castro M. Santos NC, Ricardo LH. Assessment of the "golden proportion" in agreeable smiles. Quintessence Int. 2006;37:597604

18. Magne P, Gallucci GO, Belser UC. Anatomic crown width/length ratios of unworn and worn maxillary teeth in white subjects. J Prosthet Dent. 2003;89:453-461

19. Sterrett JD, Oliver T, Robinson F, Fortson W, Kneak B, Russel CM. Width length ratios of normal clinical crowns of maxillary anterior dentition in man. J Clin Periodontol. 1999;26:153-157.

20. Hasanreisoglu U, Berksun S, Aras K, Arslan I. An analysis of maxillary anterior teeth: Facial and dental proportions. J Prosthet Dent. 2005; $94: 530-538$

21. Raj $\mathrm{V}$. Esthetic paradigms in the interdisciplinary management of maxillary anterior dentition - a review. J Esthet Restor Dent. 2013:25:295-304.

22. Abduo J. Morphological Symmetry of Maxillary Anterior Teeth before and after Prosthodontic Planning: Comparison between Conventional and Digital Diagnostic Wax-ups. Med Princ Pract. 2016;25:276-281.

23. Tarvade SM, Agrawal G. Smile analysis: A review Part I. Int J Contemp Dent Med Rev. 2015; Article ID: 200115.

24. Tarvade SM, Agrawal G. Smile analysis: A review Part II. Int J Contemp Dent Med Rev. 2015; Article ID: 210115 